\title{
Control y disciplina en la Colonia Agrícola de Mínima Seguridad de Acacias: resocializar o dominar los cuerpos
}

\begin{abstract}
Omar Huertas Díaz
Abogado. Profesor Asociado. Especialista en Derecho Penal y Ph.D en Derecho por la Universidad Nacional de Colombia. Ph.D en Ciencias de la Educación por la Universidad Simón Bolivar. Magíster en Derecho Penal por la Universidad Libre. Máster en Derechos Humanos, Estado de Derecho y Democracia en Iberoamérica por la Universidad de Alcalá, España. Magíster en Educación por la Universidad Pedagógica Nacional. Socio de la Fundación Internacional de Ciencias Penales (FICP). Miembro de Honor de la Fundación de Victimología. Miembro Honorario Asociación Colombiana de Criminología. Correo electrónico: ohuertasd@unal.edu.co
\end{abstract}

Iván Ricardo Morales Chinome

Abogado por la Universidad Nacional de Colombia. Magíster (e) en Derecho con Profundización en Sociología y Política Criminal y becario sobresaliente de Posgrado de la Universidad Nacional de Colombia. Becario Stipendium Ernst-ReuterGesellschaft der Freunde, Förderer und Ehemaligen der Freien, Universität Berlin, Alemania. Correo electrónico: Irmoralesc@unal.edu.co

Sharita Melissa Rosero Estupiñan

Investigadora auxiliar de la Universidad Nacional de Colombia. Diplomado en Resolución de Conflictos PNUD-ESAP 2011. Reconocimiento Participante de la Escuela de Liderazgo Juvenil para la Transformación Social de la Gobernación de Nariño, la Escuela de Cultura de Paz de Barcelona, Agencia Catalana de Cooperación y el Programa de las Naciones Unidas para el Desarrollo de la Ciudadana Activa. Reconocimiento al desempeño académico 1-2013, Consejo de Facultad de Derecho, Ciencias Políticas y Sociales Universidad Nacional de Colombia.

Correo electrónico: smroseroe@unal.edu.co

\section{Resumen}

La Colonia Agrícola de Mínima Seguridad de Acacias es el modelo de un sistema de ejecución de la pena, cuya finalidad se orienta a la resocialización del sujeto recluido. Sin embargo, bajo los planteamientos de los grandes estudios sobre la prisión, tales prácticas podrían ser denunciadas como violatorias de los derechos de los reclusos y reclusas, por cuanto en el discurso oficial el modelo resocializador busca la transformación del sujeto a través de la modificación del comportamiento y el cambio interior de la persona recluida para su reinserción en la sociedad. No obstante, este dispositivo penitenciario en realidad persigue otras finalidades, las cuales son la transformación del sujeto para el aprendizaje de actividades necesarias en el sistema económico y la adopción de las prácticas disciplinarias para facilitar el gobierno penitenciario.

Palabras clave: Colonia Agrícola de Mínima Seguridad de Acacias, modelo resocializador, prisión, prácticas disciplinarias, trabajo carcelario.

\begin{abstract}
The Agricultural Colony of Minimum Security in Acacias, is a model of enforcement oriented towards the resocialization of the convict. However, following the statements made by the main studies about the prison, the resocialization practices could be denounced as violatory of the convicts rights, inasmuch as the official discourse about resocialization implies the transformation of the subject through behavior modification and the personal change of the convict, to accomplish their reinsertion to society. Nonetheless, this penitenciary disposal, in reality, goes after another finality as it is the transformation of the subject to the learning of the activities needed in the production system and the adoption of the disciplinary practices to ease the penitenciary goverment.
\end{abstract}

Keywords: Agricultural colony of minimum security in Acacias, resocialization model, prison, disciplinary practices, prison labor.

\section{Résumé}

La colonie agricole de sécurité minimale à Acacias, est un modèle de l'application orientée vers la resocialisation du condamné. Cependant, après les déclarations faites par les principales études sur la prison , les pratiques de resocialisation pourraient être dénoncés comme violatory des droits des condamnés, dans la mesure où le discours officiel à propos de resocialisation implique la transformation de l'objet par la modification du comportement et l' évolution personnelle du condamné , pour accomplir leur réinsertion dans la société. Néanmoins, cette cession penitenciary, en réalité, va après une autre finalité que ce est la transformation de l' objet à l'apprentissage des activités nécessaires dans le système de production et l'adoption des pratiques disciplinaires pour faciliter le goverment penitenciary .

Mots clés: Colonie agricole de sécurité minimale à Acacias, Modèle de resocialisation, Pénitentiaires, Pratiques disciplinaires, Le Travail pénitentiaire 



\title{
Control y disciplina en la Colonia Agrícola de Mínima Seguridad de Acacias: resocializar o dominar los cuerpos ${ }^{*}$
}

\author{
Omar Huertas Díaz \\ Iván Ricardo Morales Chinome \\ Sharita Melissa Rosero Estupiñan
}

\section{INTRODUCCIÓN}

La Colonia Agrícola de Mínima Seguridad de Acacias en el Meta es el único centro de reclusión a campo semiabierto en Colombia. Es reconocida por albergar condenados bajo un régimen de baja severidad, por cuanto en ella se encuentran internos que están próximos a cumplir sus respectivas condenas y fueron declarados responsables por conductas de baja dañosidad social.

Ante la grave crisis penitenciaria del país por el altísimo hacinamiento en los centros de reclusión, la Colonia es presentada ante la opinión pública como una institución carcelaria más humana y efectiva, por cuanto sus instalaciones y extensas áreas proporcionan un bajo índice de hacinamiento y admiten la aplicación de un tratamiento penitenciario interdisciplinar que le permite a los reclusos aprender un oficio productivo, que además de facilitar la redención de la pena y el sostenimiento económico de la Institución, también prepara a los internos para su reinserción exitosa en la sociedad, particularmente la reinserción al mercado laboral.

Esta situación corresponde al discurso oficial del ideal resocializador fuertemente criticado por los representantes de la criminología crítica y la anti psiquiatría. El llamado tratamiento resocializador disfrazado de reinserción social en realidad persigue otras finalidades, las cuales son la transformación del sujeto para el

Este artículo es resultado de la investigación de la visita a la Colonia Agrícola de Mínima Seguridad de Acacias en el departamento del Meta, Colombia, realizada el 30 de mayo de 2013 por el Grupo de Investigación: Escuela de Derecho Penal NULLUM CRIMEN SINE LEGE UN de la Universidad Nacional de Colombia, actualmente registrado con el Código COL0078909 en Colciencias. Línea de Investigación: Neopunitivismo y Derecho Penal. 
aprendizaje de actividades necesarias en el sistema económico y la adopción de las prácticas disciplinarias para facilitar el gobierno penitenciario.

Por tanto, el objeto del presente artículo es analizar de forma crítica el modelo de resocialización implementado en la Colonia Agrícola de Mínima Seguridad de Acacias y particularmente del Centro Terapéutico, a partir de la investigación y el trabajo de campo realizado por el Grupo de Investigación Escuela de Derecho Penal NULLUM CRIMEN SINE LEGE de la Universidad Nacional de Colombia.

El presente documento se divide en dos partes. La primera trata de la historia, la estructura y el modelo de resocialización de la Colonia y del Centro Terapéutico. En la segunda parte se establece una crítica al tratamiento resocializador y a las prácticas disciplinarias al interior de la Colonia, a partir de los estudios sobre la prisión y el trabajo de campo realizado.

\section{METODOLOGÍA}

\section{Enfoque de investigación: Investigación cualitativa}

La investigación desarrollada en el presente documento obedece a un proceso investigativo de carácter cualitativo, la cual posee un enfoque multimetodológico que implica un enfoque interpretativo y naturalista a su objeto de estudio. En este proceso los investigadores cualitativos tienen el rol de estudiar las cosas en sus ambientes naturales, intentando darles sentido e interpretando los fenómenos en función de los significados que las personas les otorgan. La investigación cualitativa involucra el estudiado uso y recopilación de una variedad de materiales empíricos los cuales describen momentos y sentidos rutinarios y problemáticos en la vida de los individuos (Denzin, 1994, citado en Creswell, 2000).

Para el presente caso, la investigación cualitativa se desarrollará como un proceso interrogativo y por supuesto en la comprensión fundamentada en las variadas tradiciones metodológicas de indagación que pueden explorar un problema social o humano. Los investigadores participantes tendrán la responsabilidad de construir un panorama complejo y holístico desde el análisis de la Colonia Agrícola de Mínima Seguridad de Acacias, analizando los discursos, y las visiones detalladas de los informantes en un entorno natural.

\section{Tipo de investigación}

\section{Investigación descriptiva}

Se trata de una investigación que busca describir las propiedades importantes de grupos, comunidades, o cualquier otro fenómeno. Se trata entonces de representar, reproducir, o figurar el entorno a través del lenguaje, de manera que al leer o escuchar el lenguaje se evoque el objeto representado. 
Por medio de este tipo de investigación que tendrá como principal fuente de información el trabajo de campo, se logrará caracterizar globalmente la Colonia Agrícola de Mínima Seguridad de Acacias, determinar su objeto social, describir su contexto, describir su evolución, y describir el objeto de estudio con relación al tratamiento resocializador y a las prácticas disciplinarias que allí se desarrollan.

\section{Fuentes de recolección de información}

En la investigación se harán presentes las fuentes empíricas y bibliográficas, las empíricas basadas en la experiencia y la praxis, y la bibliográfica sustentada en libros y documentos. Se tendrán como fuentes de información en la investigación, las fuentes primarias, refiriéndose a los datos obtenidos del trabajo de campo realizado por los investigadores cualitativos; de igual forma, se emplearán fuentes secundarias, empleando el de información que proviene de interpretaciones ya elaboradas por teóricos.

Con igual importancia se tiene la herramienta de la observación, ya que permitirá a los investigadores estudiar el curso natural del objeto estudiado, sin alteraciones sin modificaciones, obteniendo conclusiones de dicha realidad (Carvajal, 1998).

\section{Primera parte}

\section{HISTORIA DE LA COLONIA AGRÍCOLA DE MÍNIMA SEGURIDAD DE ACACIAS}

La Colonia Agrícola de Mínima Seguridad de Acacias es una institución penitenciaria que originalmente se fundó en el año de 1924 con la Ley 105 de 1922 , en una época en la que Colombia recibía el influjo del positivismo criminológico (Huertas, López y Malaver, 2011). La Colonia, como se conoce hoy en día, fue creada por los decretos 1138 de 1930 y 2329 de 1935, pero empezó a funcionar a partir del año de 1937, siendo reconocida como centro especial de tratamiento para los reclusos con penas menores a diez años, configurándose como un centro de mínima seguridad (Arias, 2013). La Colonia además de consolidar interesantes modelos de tratamiento, se destaca como el paso a la modernización e identidad del penitenciarismo colombiano (Acosta, 2010).

Para el día 30 de mayo de 2013, el número de reclusos en la Colonia asciende a 1100 personas $^{1}$ (Arias, 2013) ${ }^{2}$. En su interior se encuentran funcionando cinco (5) campamentos: el de Cola de Pato, Central, Guayuriba, Alcarabán, Sardinata y el

1 Información tomada de la solicitud del 12 de marzo con referencia JNUTP-od-0099 publicada en la página del Sindicato Unión de Trabajadores penitenciarios http://www.utpcolombia.org/index.php.

2 Capacidad que se debate, por el convenio que actualmente promueve el Ministerio del Interior con la población de Acacias representada en su Concejo, para el ingreso de 2000 internos más, lo cual incluiría una ampliación de las estructuras físicas del establecimiento penitenciario (Unión de Trabajadores Penitenciarios, UTP, 2013). 
Piloto, donde se localiza la Comunidad o Campamento Terapéutico cuya función especial es el tratamiento de internos con adicción al consumo de drogas.

La Colonia Agrícola de Mínima Seguridad de Acacias es el último centro de reclusión a campo semiabierto en Colombia, y es reconocida por albergar reclusos que merecen un régimen de menor severidad para las personas condenadas que hayan cumplido en otra penitenciaría no menos de la mitad de la pena, siempre que hayan tenido buena conducta y que la condena restante no exceda los cinco años, y que no hayan cometido delitos contra la libertad sexual ni terrorismo (Huertas, 2013).

Varios de los postulados con los que fue instaurada la Colonia parecen haber desaparecido, por ejemplo el destierro y la generación de riqueza a través de la colonización y el trabajo rural de los reclusos para volver productivas las tierras (Jaramillo, 2005). Sin embargo, el aprovechamiento de la mano de obra como principal elemento del discurso resocializador aún existe bajo formas distintas; hoy en día los productos agrícolas elaborados dentro de la Colonia se comercializan y son en parte fuente de los recursos para el sostenimiento de la institución.

De esta manera, el aprendizaje del trabajo agrícola obligatorio, acompañado de particulares prácticas disciplinarias como el tratamiento de la adicción al consumo de drogas, para algunos de los internos, se configura como parte característica del proceso transformador o resocializador del recluido en el interior de la Colonia. Esto en cumplimiento específico de varios de los fines de la pena, la prevención especial positiva (resocialización) y la retribución justa.

\section{Estructura arquitectónica}

La Colonia Agrícola de Mínima Seguridad de Acacias cuenta con 300000 hectáreas divididas en ocho campamentos designados como: El Central, Cola de Pato, Alcaraván, Sardinata, El Trapiche, Guayuriba, El Canario y El Piloto donde se encuentra el Centro Terapéutico.

Campamento Central: área construida $9112,76 \mathrm{~m}^{2}$. Aquí se encuentran las oficinas de la Dirección, la Telegrafía, la pequeña Clínica, los dormitorios del personal de custodia, y los talleres donde durante el día los internos desarrollan labores de carpintería, ebanistería, zapatería y sastrería.

Campamento Cola de Pato: área construida 8501,83 $\mathrm{m}^{2}$. Funciona como campamento base debido a su cercanía con el área administrativa. Es además el más próximo a Acacias. Dentro de él se desarrollan trabajos de panadería, piscicultura, ganadería, entre otros.

Campamento Alcarabán: área construida $3990 \mathrm{~m}^{2}$. Cuenta con tres patios y es considerado como uno de los más seguros dentro de la Colonia. En él las personas recluidas se encuentran en fase de observación y reciben instrucción del Servicio Nacional de Aprendizaje (SENA).

Campamento Sardinata: área construida 2426,35 $\mathrm{m}^{2}$. Está compuesto por un solo patio donde los internos se encargan de la producción de panela. 
Campamento El Trapiche: área construida $2300 \mathrm{~m}^{2}$. Aquí los internos realizan labores dirigidas al autosostenimiento de la Colonia.

Campamento Guayuriba: área construida 2364,86 $\mathrm{m}^{2}$. Destinado a reclusos de la tercera edad y para algunos de los internos cuya condena está por finalizar. Allí se hace el transbordo fluvial de las mercancías con que se abastece la Colonia.

Campamento El Canario: área Construida 2279,49 m² (Inpec, 2013).

Campamento Piloto o Centro Terapéutico: con un área construida de $600 \mathrm{~m}^{2}$, cuyo funcionamiento se dirige al tratamiento especial de los internos que enfrentan un proceso de rehabilitación del consumo de drogas.

\section{Estructura organizacional de la Colonia Agrícola de Mínima Seguridad de Acacias}

La Colonia se organiza en distintos cuerpos encargados de dinamizar el tratamiento penitenciario de la persona condenada, entre los más importantes está el Consejo de Disciplina integrado por profesionales en psicología, sanidad, educación, trabajo social y derecho; la Junta de Patios que define la fase de resocialización del interno; la Junta de Trabajo enfocada en los diferentes programas productivos; la Junta de Evaluación de Clasificación de Fases, la cual evalúa en qué momento del tratamiento se halla el sujeto recluido; la Junta de Seguridad; la Junta de Alimentación; y el Comité de Derechos Humanos, un espacio donde los internos cuentan con un representante.

Por otra parte, la guardia de la Colonia está integrada por profesionales en un setenta y cinco por ciento (75\%), es la más antigua del país, y ser parte de ella es un reconocimiento a la experiencia y formación de sus integrantes, quienes reciben un $20 \%$ más en su prima de salario respecto a otros guardianes del país.

\section{La resocialización del sujeto en la Colonia Agrícola de Mínima Seguridad de Acacias}

En este aparte se precisa la noción y el modelo de "Resocialización" al interior de la Colonia. Para hablar del concepto se toman algunos referentes normativos, y se presenta la aplicación de esta noción en el interior del Centro Terapéutico de la Colonia.

\section{Noción}

En el discurso oficial el derecho penal se instituye como un sistema dirigido a controlar el delito a través de la imposición de penas; su fin se materializa cuando los ciudadanos se abstienen de cometer delitos y quienes ya los cometieron no reinciden. $\mathrm{Su}$ finalidad se concreta en las funciones de la pena, tales como la prevención general, y la prevención especial; esta última desarrollada en la ejecución de la pena donde se lleva a cabo el tratamiento penitenciario para la resocialización. 
De acuerdo con la Ley 65 de 1993 la resocialización es el fin esencial del tratamiento penitenciario ${ }^{3}$, debido a que la ejecución de la pena tiene como pretensión reacoplar al individuo condenado ${ }^{4}$. Así, la resocialización bajo lineamientos de la Ley 599 de 2000, consolida una funcionalidad restaurativa de la pena, dando paso a la concepción de reinserción de quienes hayan infringido el orden de la sociedad (Gaceta del Congreso, 1995). De tal forma, el concepto de resocialización en la Colonia se entiende como un proceso de reamoldamiento del sujeto para la convivencia en sociedad (Sentencia C-148, 1998).

El tratamiento penitenciario, la resocialización para la reincorporación social del individuo condenado, es entendido como la labor fundamental de los funcionarios de la Colonia, quienes acuñan en esta institución penitenciaria un trabajo similar al que se desarrolla en una fábrica ${ }^{5}$, frase que evoca a Foucault (2002) al hablar de las modernas prácticas de reclusión, la prisión se instituye en una fábrica de sujetos modelados de acuerdo con las necesidades imperantes de la sociedad

\section{El tratamiento resocializador en el interior de la Colonia Agrícola de Mínima Seguridad de Acacias}

El tratamiento resocializador dentro de la Colonia está compuesto por los siguientes elementos: la clasificación de acuerdo con el perfil del recluso, la disciplina en la institución y la modulación de la pena de acuerdo con el avance o retroceso dentro del tratamiento.

\section{La clasificación de acuerdo con el perfil del recluso}

Las personas recluidas en la Colonia cumplen condenas no mayores a 5 años, generalmente condenados por delitos de inasistencia alimentaria, hurto, lesiones personales y porte de estupefacientes cometidos en grandes ciudades como Bogotá ${ }^{\text {. }}$

Por otro lado, la Colonia recibe internos de otros centros de reclusión, especialmente de Bogotá, del Complejo Carcelario y Penitenciario Metropolitano

3 En concordancia se presentan las apreciaciones de los funcionarios de la Colonia, cuando entienden la resocialización como el eje central de la actividad de la Institución. En este sentido, se hace gala al comentario del Director del establecimiento, quien en respuesta sobre el significado de los internos en la Colonia afirmaría que "son la razón de ser de la Institución [es] su tratamiento, y resocialización lo que se persigue".

4 Así lo asignaba la Ley 100 de 1980, punto de referencia para la cual la pena tenía una función protectora de la persona y preventiva del delito, esto es, la resocialización del recluido como función principal de la pena, después de haber retribuido el daño.

5 En palabras del Director de la Colonia se dice que el establecimiento se constituye como "una fábrica de hacer pan [lugar en el que se] busca convertir a los internos en más humanos".

6 En palabras de uno de los guardias el interno se describe como "el 'ñero', el carterista de Bogotá, aquel que no sabe hacer nada, y que proviene de un ciclo social abierto, pues no tiene ninguna figura familiar que lo guíe". 
"La Picota" . Debido a la grave crisis carcelaria que vive el país ${ }^{8}$ se hace necesario el envío de las personas reclusas a cárceles con menores índices de hacinamiento carcelario, a pesar de la obligación legal de recluir personas preferiblemente con vocación campesina en la Colonia9.

Por otro lado, en la clasificación de los internos se tiene en cuenta su identidad religiosa, esto con el fin incluir su convicción dentro del tratamiento resocializador, por lo cual solo se permite el ingreso a la Colonia de las iglesias a las que pertenecen los internos.

Por último, en el momento del ingreso en la Colonia se definen los reclusos con adicción al consumo de drogas, quienes voluntariamente pueden ser parte del programa de desintoxicación en el Centro Terapéutico localizado en el campamento Piloto (Huertas, et al., 2011).

\section{La disciplina en el interior de la institución}

La disciplina dentro del establecimiento penitenciario se impone a través de la estructura arquitectónica y organizativa de la Colonia, ello sin olvidar las diferentes prácticas disciplinarias tales como el aislamiento, el trabajo y la modulación de la pena. Es de interés particular que la Colonia Agrícola no adopta el modelo de Solitary confinement norteamericano, en el que los reclusos permanecen todo el tiempo dentro de celdas individuales, sino que tiene un profundo acercamiento con el modelo de Silent system, donde los reclusos realizan labores de manufactura durante una jornada laboral de ocho horas, que en el caso de la Colonia se cumple en labores agropecuarias (Melossi \& Pavarini, 1980).

\section{La modulación de la pena de acuerdo con el avance o retroceso dentro del tratamiento}

La modulación de la pena en el tratamiento penitenciario hace referencia al conjunto de instrumentos enlazados, dedicados a operar sobre el sujeto que se va a tratar y se visibilizan distintos matices del procedimiento penitenciario. De forma específica se hace alusión a la clasificación, la terapia múltiple $\mathrm{y}$, finalmente, a una aproximación al mencionado Centro Terapéutico.

7 Afirman los guardianes "la Colonia hace las veces de patio trasero de la Picota".

8 A marzo de 2013, la capacidad real de las cárceles a nivel nacional permite el alojamiento de 75726 internos y en realidad alberga 116370 personas. Lo que indica que los niveles de hacinamiento hoy en los penales es de 53,7\%, es decir, hay 40644 personas recluidas por encima de la capacidad de los centros carcelarios. Esta información fue obtenida en el marco del proceso de seguimiento de varias sentencias de tutela que ordenan el cierre de cárceles realizado por la Defensoría del Pueblo.

9 Ley 65 de 1993. Código Penitenciario y Carcelario, artículo 28. Colonias Agrícolas: son establecimientos para purgar la pena, preferencialmente para condenados de extracción campesina o para propiciar la enseñanza agropecuaria. 


\section{Clasificación en las fases de tratamiento}

En la Colonia Agrícola de Mínima Seguridad de Acacias, los internos se catalogan en diferentes fases según su progreso en el tratamiento. De manera que de acuerdo con su avance se ubican en distintos espacios del centro penitenciario; por ejemplo, los reclusos de la fase avanzada practican labores externas como piscicultura, aseo en unidades administrativas, panadería, carpintería y ganadería.

A saber, cada campamento aplica diferentes formas y prácticas de presencia que influyen en la instrucción para la reincorporación social del sujeto. Las medidas van desde silencios que permiten al personal una vigilancia diferenciadora, capaz de analizar las conductas de los internos, para que en un momento determinado sea posible apreciarlas, sancionarlas, o aún estimularlas, hasta la generación de distintas expectativas sobre los sujetos en cada campamento, cuestión que evalúa el Consejo de Evaluación y Tratamiento, que modifica y señala las fases por las cuales pasa el interno.

\section{La terapia múltiple y sus fases}

En la Colonia Agrícola de Mínima Seguridad de Acacias, el tratamiento penitenciario combina distintas prácticas, así integra el trabajo y la educación de carácter rural, la atención psicológica y médica como partes esenciales para el proceso resocializador de la persona recluida.

En este marco, la distribución de los internos en los campamentos corresponde a las fases alcanzadas dentro de su tratamiento. Por ejemplo, la Fase alta en la que se adelanta el proceso de reversión, se encuentra en el Campamento de Alcarabán, el cual hace las veces de un centro de observación, identificación y clasificación de los internos que recibe la Colonia, donde al tiempo las personas reclusas reciben instrucción del Servicio Nacional de Aprendizaje - SENA, sin necesidad de salir del lugar de internamiento ${ }^{10}$.

Los internos que se encuentran en el Campamento Central son aquellas personas que están por lo menos a seis meses de salir de la Colonia, lo anterior según la explicación de las autoridades, se da de acuerdo con el tiempo y al avance que los internos hayan tenido, comprendiendo que tales labores se encomiendan a quienes han respondido a las distintas fases de resocialización.

En esa medida, el trabajo y la educación, como concreción de la terapia múltiple, contempla beneficios para la redención de la pena y estímulos como permisos. Así quienes no tienen más requerimientos y hayan cumplido con tres cuartas $(3 / 4)$ partes de su condena, se encontrarán en una etapa del tratamiento que los puede hacer merecedores de permisos hasta de setenta y dos (72) horas.

10 Esto constituye evidencia de las afirmaciones de Santoro (2008) quien consideraba la necesidad de articular distintos métodos para la reeducación del individuo, siendo insuficiente el mero hecho de privar de la libertad al individuo. 
Se añade, por otro lado, que el tratamiento de los internos ocasionalmente incluye actividades recreativas y campeonatos durante el tiempo que no se dedica al trabajo o al estudio, pues como máximo estas diligencias pueden emplear ocho y seis horas por cada día interno del recluso.

Igualmente, en la búsqueda de una estrategia integral dirigida al interno, se consolida como eje central el enfoque ambiental, a través del cual se intenta sembrar en el recluso el sentido del cuidado por la naturaleza, por su cuerpo, pero más aún de su libertad ${ }^{11}$.

En suma, los proyectos que maneja la colonia penal agrícola se pueden ver desde cuatro puntos: resocialización del interno, redención de la pena, beneficio económico y ambientalismo. De ahí que ante la negativa del interno para hacer parte de proyectos educativos o de producción, se afecte más que por un castigo físico, con su escaso o nulo avance a través de las fases de clasificación y redención de la pena, que se traduce en la dificultad de obtener una rebaja de tiempo de reclusión, además del impedimento de recibir un pago o estímulo por su actividad productiva.

Finalmente, la terapia múltiple desarrolla una estricta rutina manejada directamente por el personal y algunos de los internos, así a los mecanismos de enseñanza de "buenos comportamientos", se incorporan prácticas que afianzan los valores que se consideran positivos, por ejemplo, la disciplina y el buen uso del tiempo $^{12}$. Para el caso de la Colonia se fijan horarios regulares y estrictos tales como levantarse a las 5 a.m., posteriormente, bañarse, para que a partir de las: 5:45 a.m. las personas recluidas "hagan sus necesidades fisiológicas", de manera que a las 6 a.m. los internos se presenten al desayuno y así puedan estar listos para realizar sus labores internas o externas hasta las 11 a.m., hora del almuerzo, para que más adelante terminen sus labores y reciban la cena a las 4 p.m. Llama la atención la denominada "hora del silencio" a las 8 pm, momento donde el silencio reina y obliga, permitiendo a los dragoneantes tener toda posibilidad de escuchar cualquier sonido. Finalmente, se aclara que en cada una de las actividades y tiempos dentro de la Colonia, un guardia que ordena, dirige y vigila el horario diseñado para los internos asiste de manera constante.

Como se mencionó anteriormente atendiendo a un modelo de tratamiento multifocal, en la Colonia se encuentra la atención psicológica y médica, principalmente en la Comunidad Terapéutica, la cual no solo cuenta con el personal de seguridad, sino además por un cuerpo de profesionales en psicología, trabajo social y eventualmente médicos, que en conjunto apoyan el proceso resocializador de los sujetos con adicción a las drogas.

11 Creando un símil entre la forma que se interioriza la protección de los diferentes frutos con el cuidado de su misma libertad, uno de los guardianes afirmó: "Así como cuida del fruto, del cerdo, [...] así aprenderá a cuidar de su libertad".

12 Estos factores representan lo que se ha denominado como control social (Carrillo, 1996). 


\section{El modelo resocializador en el Centro Terapéutico}

El modelo resocializador aplicado en el Campamento Piloto o Centro Terapéutico de la Colonia Agrícola de Mínima Seguridad de Acacias se concreta en un sistema terapéutico que impulsa el aprendizaje social de pautas de comportamiento, ordenando de forma detallada las conductas impulsivas, la expresión de sentimientos, la verbalización y revisión de la relación individuo-sociedad, aún desde el cuestionamiento del interior del sujeto condenado. Es pues, un tratamiento previo a la intervención penitenciaria, dedicado a personas que no enfrentarían de igual forma el internamiento como retribución y búsqueda de la integración social.

Los internos en este campamento son ordenados, sumisos e incluso estrictos entre ellos al momento de fijarse en su comportamiento, su vínculo es análogo al de una familia, en donde cada uno tiene sus roles.

Los mecanismos y procedimientos en la Colonia Agrícola de Acacias han sido influenciados por los lineamientos trazados por la Oficina Federal de Prisiones en Estados Unidos -Bureau Federal-(Arias, 2013). Este último contempla entre los tipos de penitenciarías los establecimientos de mínima seguridad, el "Centro terapéutico" dentro de una colonia penal es un modelo pensado desde el control. En Colombia se trata de un proyecto de prevención integral que inició en el año 1992 en convenio con el Ministerio de Justicia y Naciones Unidas. El campamento Piloto es el lugar donde los internos con dependencia de las drogas asumen ser parte de un tratamiento de desintoxicación, un proceso que se constituye como la principal alternativa terapéutica para dejar el consumo de drogas.

En la visita se permitió el ingreso a una reunión denominada "Rutina Terapéutica", una de las prácticas dirigidas al cambio integral de los hábitos de consumo de drogas e insubordinación del interno. Al momento de ingresar, alrededor de catorce internos se encuentran desarrollando una especie de ceremonia en compañía de los administrativos del centro penitenciario, entre ellos, el director. Se trata del reconocimiento del avance para algunos internos en su proceso de resocialización, situación que los hace merecedores de una camiseta de color rojo. Siendo el color de camiseta un indicador de la etapa del tratamiento en que se halla la persona recluida. La camiseta roja significa "desafío al cambio", la azul "proyección” y la amarilla "reinserción".

En la ceremonia, los internos entonan, además del Himno Nacional, canciones como la siguiente:

En qué lugar anidaré mis sueños nuevos y quien me dará una mano para volver a empezar [...] volver a empezar que no termina el juego [...] volver a empezar que no se apague el fuego.

Posteriormente, los internos corren en conjunto y en un círculo comparten con los investigadores visitantes, se saludan al mismo tiempo y repiten el nombre de cada uno de los internos al presentarse. Uno de los reclusos, quien no usaba de manera impecable su uniforme, fue señalado por el interno de la fase más avanzada del 
tratamiento y le ordena no estar más "desalatajado". Fue interesante ver cómo los internos replicaban sus gestos, además llama la atención que dos de los internos portaban un aviso colgado en su pecho en el que decía "incomunicado", letrero que señalaba la prohibición de hablar; restricción que fue justificada e impuesta por los mismos internos, quienes expresaron que tal limitación se aplicó porque ellos incumplieron una de las doscientas normas -no escritas- que los rigen.

Finalizada la ronda con los visitantes y acompañados con un guardia, es posible preguntarle a uno de los internos sobre su concepto de libertad, quien responde: "Es dejar de encerrarse en sí mismo [...] es estar y ser parte de una familia". Así mismo, dice: "Lo bueno es que la libertad y lo bueno coincidan".

Relacionada con estas palabras, en un mural cerca de un salón de lecturas, una frase expresa la razón de hallarse recluido en la Colonia Agrícola de Mínima de Seguridad de Acacias: "Estamos aquí porque no existe refugio alguno donde escondernos de nosotros mismos [...] mientras la persona no se confronte con los demás, [...] no comunique sus secretos no hallará reposo". Enunciado que hace pensar, ¿hasta qué punto se cuestiona al sujeto recluido, donde para estar bien, según se le exigen un sinnúmero de parámetros generalizados? Esta idea es un poco incoherente, se deja la adaptación a consideración de la editora para evitar cambios del sentido de la idea.

Siguiendo con la rutina, los internos se dicen y comparten lo que van a hacer durante el día. Y para el cumplimiento de sus cometidos, según nos indican, la vigilancia no está tanto en manos de la guardia sino en el mismo grupo de internos, quien ejerce la presión para el cambio sobre cada uno de sus integrantes.

\section{Segunda parte}

\section{CRÍTICA AL MODELO RESOCIALIZADOR DE LA COLONIA AGRÍCOLA DE MÍNIMA SEGURIDAD DE ACACIAS}

El modelo resocializador de la Colonia Agrícola de Mínima Seguridad de Acacias se fundamenta en el aprendizaje de labores agropecuarias y en la aplicación de prácticas disciplinarias para la transformación de los reclusos para su posterior reinserción a la sociedad.

Sin embargo, el trabajo carcelario no fue introducido a las prisiones de acuerdo con una concepción humanista que buscara la adquisición de conocimientos técnicos y profesionales por parte de los reclusos para su reinserción a la sociedad, por el contrario, su introducción obedeció a una etapa específica del desarrollo industrial y la necesidad de mano de obra barata que controlara los precios y las demandas de las organizaciones obreras. Situación que no se presenta en el caso colombiano, por cuanto no existen tales necesidades dentro del sistema económico colombiano (Bonfil, 2013). 
Por otro lado, las prácticas disciplinarias constituyen el pilar fundamental del mantenimiento del orden y el gobierno penitenciario para que los reclusos aprendan las técnicas febriles y adopten una posición de sumisión frente a la institución penitenciaria.

Es así como, el tratamiento penitenciario aplicado a las personas privadas de la libertad en la Colonia, en realidad busca la sumisión de los reclusos ante las autoridades carcelarias, situación que facilita el orden dentro de la institución, mientras los reclusos realizan labores agrícolas que al salir del establecimiento no van a utilizar en sus lugares de procedencia debido a la falta de demanda de mano de obra para labores del campo y a que los reclusos de la Colonia provienen principalmente de grandes centros urbanos. Tratar esta situación corresponde al objeto de la segunda parte del presente artículo.

\section{El papel del trabajo y el aprovechamiento de la mano de obra de los reclusos}

Los grandes estudios sobre la prisión ${ }^{13}$ son coincidentes en afirmar, en primer lugar, que las formas específicas de castigo corresponden a una etapa determinada del desarrollo económico y, en segundo lugar, que la principal finalidad de la prisión consiste en la transformación de los individuos. Así pues, la esclavitud como forma punitiva resulta impracticable fuera de una economía de ese tipo, el trabajo carcelario es imposible sin fábricas o industrias, las sanciones pecuniarias no son posibles sin una economía monetaria. Por otra parte, la desaparición de un determinado sistema de producción acarrea la inaplicabilidad de su sistema punitivo (Kirchheimer y Rusche, 1984, p. 4).

Así, en una economía de esclavitud en la que disminuye la oferta de mano de obra esclava y aumenta su demanda, resulta imposible rechazar la esclavitud como forma punitiva. Durante el feudalismo, por ejemplo, no solo no se pudo continuar utilizando esta forma de pena, sino que no se encontró otro método adecuado para el empleo de la fuerza de trabajo de los convictos. Un retorno a los viejos métodos, pena de muerte y castigos corporales, fue por lo tanto necesario, ello además porque la introducción de penas pecuniarias para todas las clases sociales resultaba imposible por razones económicas. Por otra parte, los institutos correccionales alcanzaron su máximo desarrollo durante el mercantilismo y proporcionaron gran ímpetu al nuevo modo de producción, para posteriormente ser abandonados por el decaimiento de la importancia económica de dichos institutos provocado por el surgimiento de la fábrica (Kirchheimer y Rusche, 1984, p. 4).

13 Puede afirmarse que la elección de nuestro marco teórico es arbitraria, sin embargo, los tres textos utilizados en este aparte son imprescindibles de cualquier estudio sobre la prisión. Por otro lado, son textos indispensables en el análisis de recientes estudios sobre las prisiones y la sociología del castigo (Loïc Wacquant y David Garland). 
Esto explica la razón de la introducción del trabajo fabril en los establecimientos carcelarios desde finales del siglo XVIII y principios del siglo XIX, pues se adoptó para suplir las necesidades del aparato productivo, a través de dos formas; en primer lugar, en la utilización de la mano de obra de los reclusos bajo esquemas productivistas y competitivos (incluso con intervención directa del sector privado en la organización y gestión del trabajo carcelario) en la elaboración de productos para el mercado; y en segundo lugar, en la transformación del criminal rebelde en un sujeto disciplinado y adiestrado para el trabajo de la fábrica, es decir, las instituciones penitenciarias funcionaban como fábrica de obreros aptos para el trabajo asalariado (Melossi \& Pavarini, 1980).

Este es el principal resultado de la investigación sobre la experiencia penitenciaria de Estados Unidos de Melossi y Pavarini, donde el Estado norteamericano "inventó" la penitenciaría como una alternativa al control social a través del internamiento institucional forzoso de las masas de pobres, ociosos y vagabundos en estas instituciones donde la administración pública debía encargarse de su educación por medio del trabajo y el aprovechamiento de la fuerza del trabajo carcelario, especialmente en las manufacturas.

Sin embargo, Melossi \& Pavarini (1980) advierten que la penitenciaria como manufactura o fábrica no fue realmente una célula productiva, ni el trabajo penitenciario tuvo efectivamente la finalidad de crear una utilidad económica. Pues aunque históricamente se buscó hacer del trabajo carcelario un trabajo productivo, en la realidad este intento casi siempre fracasó: desde el punto de vista económico, la cárcel apenas ha podido llegar a ser una empresa marginal. Por eso, como actividad económica, la penitenciaria nunca ha sido útil, y en ese sentido, no es correcto hablar de la cárcel como manufactura o como fábrica (de mercancías). En cambio, en una segunda finalidad de producción perseguida por la cárcel, al menos en sus orígenes, tuvo éxito la transformación del criminal en proletario:

En eso consiste la verdadera "invención penitenciaria": "la cárcel como máquina" capaz de transformar al criminal violento, febril, irreflexivo en detenido, disciplinado y mecánico. En definitiva, una función no sólo ideológica sino también, aunque sea en forma atípica, económica: o sea la producción de sujetos aptos para una sociedad industrial, la producción, en otras palabras, de proletarios a través del aprendizaje forzado, en la cárcel, de la disciplina de fábrica (Melossi \& Pavarini, 1980, p. 190).

La transformación de los sujetos se intentó en Estados Unidos a través de dos modelos: el modelo de Auburn y el modelo de Filadelfia. La prisión realiza dicha transformación por la progresiva reducción de la personalidad criminal y la conversión del recluso en un sujeto de necesidades a través de la clasificación criminal y la segregación.

Esta transformación se completa por medio del trabajo y la disciplina institucional. En primera medida, en su dimensión ideológica se establece que el trabajo es la única 
solución para la satisfacción de las necesidades de los no propietarios y, por otro lado, la dimensión pedagógica instaura el trabajo como modelo educativo. Como segunda consideración, la disciplina es de corte casi militar para una institución que busca organizar y gestionar momentos de vida colectiva, también se instauran mecanismos para lograr la uniformidad de los reclusos a través de la organización de la administración penitenciaria en términos jerárquico-militares, pues los carceleros generalmente provienen de cuerpos militares o las cárceles son administradas directamente por instituciones militares. Esto implica la sujeción de los reclusos a estrictos reglamentos que obligan a llevar el uniforme de determinada manera, tener el cabello corto y cumplir estrictos horarios en las labores cotidianas al levantarse, comer, dormir, lavarse, entre otras.

En otro orden de ideas, Michel Foucault (2002, p. 235) afirma que "la prisión se funda tanto sobre la forma simple de la privación de libertad como la transformación técnica de los individuos". En cuanto a lo primero, la privación de libertad se constituyó en la pena por excelencia en una sociedad en que la libertad es un bien que pertenece a todos de la misma manera, su pérdida tiene pues, el mismo precio para todos, mejor que la multa, la prisión es el castigo igualitario. Claridad en cierto modo jurídica de la prisión. Además permite cuantificar exactamente la pena según la variable del tiempo. Hay una forma salario de la prisión que constituye, en las sociedades industriales, su evidencia económica.

Pero "la evidencia de la prisión se funda también sobre su papel, supuesto o exigido, de aparato de transformar los individuos". Este doble fundamento -jurídico económico de una parte, técnico disciplinario de otra- ha hecho parecer la prisión como la forma más inmediata y más civilizada de todas las penas (Foucault, 2002, p. 235).

De acuerdo con todo lo anterior, "la prisión ha sido desde el comienzo una detención legal encargada de un suplemento correctivo, o también, una empresa de modificación de los individuos que la privación de libertad permite hacer funcionar en el sistema legal". En suma, el encarcelamiento penal, desde el principio del siglo XIX ha cubierto a la vez la privación de la libertad y la transformación técnica de los individuos (Foucault, p. 235).

Esta transformación de los individuos elaborada en la prisión, se lleva a cabo por ser un aparato disciplinar exhaustivo. En varios sentidos:

debe ocuparse de todos los aspectos del individuo, de su educación física, su aptitud para el trabajo, de su conducta cotidiana, de su actitud moral, de sus disposiciones, la prisión, mucho más que la escuela, el taller o el ejército, que implican siempre cierta especialización, es omnidisciplinaria. Además, la prisión no tiene exterior ni vacío, no se interrumpe, excepto una vez acabada totalmente su tarea, su acción sobre el individuo debe ser ininterrumpida: disciplina incesante. En fin, un poder casi total sobre los detenidos (Foucault, 2002, p. 238). 
Para el autor, este poder disciplinar se fundamenta en tres principios:

Primer principio. El aislamiento. Aislamiento del penado respecto del mundo exterior, de todo lo que ha motivado la infracción, de las complicidades que la han facilitado. Aislamiento de los detenidos los unos respecto de los otros. No sólo la pena debe ser individual, sino también individualizante (Foucault, 2002, p. 239).

Segundo principio. El trabajo como un agente de la transformación penitenciaria. El preso a partir de su entrada al establecimiento pasará a estar poco a poco, por la fuerza de un hábito, primero puramente externo, pero pronto transformando en una segunda naturaleza, a familiarizarse con el trabajo (Foucault, 2002, p. 242).

Tercer principio. La prisión tiende a convertirse en un instrumento de modulación de la pena. La pena debe ser individualizada a partir del individuo castigado, objeto de una materia controlada de transformación, el individuo en detención inserto en el aparato carcelario, modificando por él o reaccionando a él (Foucault, 2002, p. 247).

A partir de los anteriores estudios, se puede afirmar entonces que el trabajo carcelario aparece en una etapa determinada del desarrollo económico que impuso la necesidad de utilizar la mano de obra reclusa para el funcionamiento del sistema industrial, y no para enseñar un oficio que les permitiera a los internos su reinserción social.

En el caso de la Colonia, el sistema económico colombiano no necesita del trabajo agropecuario realizado por los reclusos que al cumplir sus respectivas condenas encuentran que lo aprendido dentro de la institución penitenciaria es inútil y no les permite reinsertarse en la sociedad.

\section{Las prácticas disciplinarias del tratamiento resocializador para el orden y el gobierno penitenciario}

Las técnicas disciplinarias aplicadas en la Colonia Penal de Mínima Seguridad de Acacias con un fin resocializador consisten en realidad en la transformación de los individuos en sujetos dóciles y útiles adaptados a la vida en prisión y no al logro de la reinserción de los reclusos a la sociedad (Arévalo y Bolaños, 2012).

En la Colonia y particularmente en el Centro Terapéutico se aplica un tratamiento penitenciario denominado "Metodología pedagógica socializadora". "Esta metodología es un conjunto de técnicas cuyo objetivo es gestionar de forma eficiente y eficaz el gobierno de los detenidos que acceden a este programa, operando sobre una nueva selectividad", en este caso, en los intramuros del sistema penal, es un 
escenario complejo en el cual a la par que se segrega y se neutraliza se realizan intentos por modificar la conducta de los detenidos (Mouzo, 2012, p. 107).

El cuestionamiento más fuerte para este tipo de tratamiento resocializador se fundamenta en que por sus características la modificación de la conducta no está dirigida a la integración social del individuo, sino antes bien, se orienta a adecuar a los sujetos hacia el interior del centro penitenciario.

A pesar de que el trabajo y la educación para la libertad al interior de los centros de reclusión conforman el discurso paradójico que sustenta la existencia de la prisión (García, 1975) hay que reconocer que estos ideales se han marcado desde un inicio, por una línea de fracaso del sistema penal para la resocialización del sujeto, y su efectividad al momento de definir a los sujetos reincidentes (Hurtado, 1994).

Partiendo de reconocer este fracaso de la idea de resocialización al momento de legitimar varias de las medidas penitenciarias que resultan invasivas hacia la persona recluida, se refuerza la idea de una sociedad que ha adquirido en su concepción la existencia de un contexto de riesgo, donde la función del tratamiento individualizado se dirige hacia el control (Mouzo, 2012).

Así pues, la resocialización se constituye en un conjunto de prácticas de exclusión social (Mouzo, 2012), uno de los fines de la ejecución de la pena no expresos en el sistema penal. Así, paralelo a lo que Foucault (2002) señaló como una forma de administración de los ilegalismos, capaz de otorgar en determinados sujetos el ejercicio del delito, aquí se entiende que la formación que dice adquirir en la reincorporación del individuo a la sociedad, logra por el contrario, en la mayoría de casos, incorporar a los sujetos hacia el interior del establecimiento penitenciario.

Así pues, este conjunto de técnicas dirigidas a transformar la conducta desde el interior del sujeto resulta efectivo a la hora de la reformación del recluido para el interior de la cárcel, y no para el exterior. Esto debido a que parte clave de una reeducación para la integración o reformación para la libertad consistiría en reforzar la capacidad de cada sujeto para determinarse. Punto que se desconoce al impedir al sujeto servirse del propio entendimiento, sin la dirección de otro (Kant, 2007). Esto es el autogobierno, una dimensión sine qua non para el desarrollo del hombre en la sociedad, que ante las variadas, detalladas y numerosas limitaciones que enmarca el estar recluido en el Centro Terapéutico, parece ir en contra del fin resocializador o readaptador del interno a la sociedad.

En ese sentido, cabe decir que el modelo de resocialización aplicado en la Colonia y en el Campamento Terapéutico reduce a tal punto la actuación del interno, que su comportamiento depende enteramente de direccionamientos externos, tales como horarios infalibles, la vigilancia y señalamiento de su comportamiento incluso desde sus mismos compañeros. Limitaciones tan severas que llegan a marcar a la persona recluida con anuncios como el de "incomunicado", conducen solo algo "poner al individuo al margen de la conducción de su propia existencia" (Hurtado, 1994, p. 88), haciéndolo material perfecto de la dinámica penitenciaria, por su dependencia y pertenencia a ella. 
Se entiende entonces que la justificación de las prácticas penitenciarias y quizá de la prisión es identificar a quien ha de excluirse de la sociedad, una especie de etiqueta (Lemert, 1964) donde la cuestión aquí señalada no se refiere solo al obstáculo que implica tener un historial prontuario al momento de reincorporarse a la vida social, sino a la dependencia del sujeto interno a la institución penitenciaria ${ }^{14}$.

Por todo lo anterior, consideramos que la ejecución de la pena en la Colonia genera a largo plazo la ocasión de hacer de un grupo determinado de reincidentes, por cuanto el llamado tratamiento penitenciario para la resocialización aplicado en esta institución, en realidad consiste en la aplicación de unas determinadas prácticas disciplinarias para mantener el orden carcelario combinado con el aprendizaje de labores agropecuarias que les van a resultar inútiles a los reclusos cuando hayan cumplido su condena.

\section{CONCLUSIONES}

El tratamiento resocializador aplicado en la Colonia Agrícola de Mínima Seguridad de Acacias compuesto por la clasificación según el perfil del recluso, la disciplina en la institución y la modulación de la pena de acuerdo con el avance o retroceso dentro del tratamiento, no cumple el papel de resocialización asignado por el discurso oficial.

El aprendizaje de labores agropecuarias, como elemento del tratamiento penitenciario en la Colonia, es inútil para lograr la resocialización, por cuanto al salir del establecimiento los reclusos no van a utilizar estos conocimientos en sus lugares de procedencia, debido a la falta de demanda de mano de obra para labores del campo ya que los reclusos de la Colonia provienen principalmente de grandes centros urbanos.

El conjunto de técnicas disciplinarias dentro de la Colonia dirigidas a transformar la conducta desde el interior del sujeto, resulta efectivo a la hora de la reformación del recluido para el interior de la cárcel, pero no para el exterior.

El tratamiento resocializador en la Colonia facilita la creación de un grupo de reincidentes por cuanto en vez de enseñar actividades útiles para el mercado convierte a los reclusos en individuos sumisos y funcionales a la vida en reclusión.

Es necesario hacer una revisión profunda de la función de las prisiones en el país, por cuanto a través de la aplicación de los modelos de resocialización existentes se facilita la reincidencia de las personas después de haber cumplido sus respectivas condenas.

14 En la visita uno de los internos menciona que uno de sus compañeros insistió en la comisión de un delito con el ánimo de regresar a la Colonia Agrícola de Mínima Seguridad de Acacias, no solo por el nivel de vida que tenía, sino por la seguridad que de lo externo le representaba. 


\section{REFERENCIAS}

Acosta, D. (2010). Sociología en el penitenciarismo. Escuela Penitenciaria Nacional: Instituto Nacional Penitenciario y Carcelario, INPEC.

Arévalo, S. y Bolaños, P. (2012). Aspectos que inciden en la inadecuada política criminal del Estado del Sistema Penitenciario colombiano durante los últimos años. Revista Logos Ciencia \& Tecnología, 4(1), 169-181.

Arias, D. A. (2013). Solicitud Información acerca del proyecto "Complejo Acacias". Bogotá, Colombia: Oficio N. JNUTP-OD-0099 (12 de marzo de 2013). (Presidente Nacional Unión de Trabajadores Penitenciarios UTP).

Artículos Asociación de servidores públicos del Sistema Penitenciario y Carcelario colombiano (2013). Unión de trabajadores penitenciarios UTP. Recuperado de http://www.utpcolombia.org/component/content/article/8-noticias/618socializan-llegada-de-2-000-presos-a-acac\%C3\%ADas

Bonfil, C. (2013). Los retos del proceso de reinserción social en el Estado mexicano; frente a la figura del penitenciarismo en Colombia. Revista Logos Ciencia \& Tecnología, 5(1), 51-62.

Carrillo, I. ( 1996). El control social formal. Revista de la Facultad de Derecho de México, 209-210, 31-45.

Carvajal, L. (1998). Metodología de la investigación. Cali: Fundación para Actividades de Investigación y Desarrollo, FAID.

Corte Constitucional Colombia. (06 de mayo, 1998). Gaceta del Congreso, Año 4, N. ${ }^{\circ}$ 61. Bogotá. Sentencia C-148. Bogotá (05 de abril de 1995).

Congreso de la República, Colombia (20 de agosto, 1993). Ley 65 de 1993. Diario Oficial N. 40 999. Bogotá.

Creswell, J. (2000). Investigación cualitativa y diseño investigativo. (Trad. María José Llanos Pozzi). Buenos Aires: Universidad de Buenos Aires, Facultad de Ciencias Sociales - Sociología.

Foucault, M. (2002). Vigilar y castigar. Argentina: Siglo Veintiuno Editores.

García Ramírez, S. (1975). La prisión. México: Fondo de Cultura Económica.

Huertas O. (2013). Política Criminal del Estado colombiano y los derechos de las personas privadas de la libertad: análisis legislativo y jurisprudencial de la Corte Constitucional. Revista Logos Ciencia \& Tecnología, 5(1), 51-62.

Huertas, O., López, L. L., y Malaver, C. M. (julio-diciembre, 2011a). La Colonia Penal de Oriente. Último rezago del positivismo jurídico penal. Diálogos de Saberes, (35), 139-150.

Huertas, O., López, L. L., y Malaver, C. M. (2011b). Comunidad terapeutica y su programa penitenciario. Colonia Penal de Oriente. Revista Criterio Jurídico Garantista, 3(5), 52-67. 
Hurtado, P. (1994). Michel Focault un proyecto de ontología histórica. Madrid: Librería Agora S.A.

Instituto Nacional Penitenciario y Carcelario - INPEC (2013a). Recuperado de http:// www.inpec.gov.co/portal/page/portal/Inpec/SeccionInpeccomoinstitucion/ EstablecimientosPenitenciarios/REGIONAL\%20CENTRAL/CAMIS\%20 ACACIAS

Instituto Nacional Penitenciario y Carcelario - INPEC (2013b). Recuperado de http:// www.inpec.gov.co/portal/page/portal/Inpec/SeccionContratacion/resultados buscador?cx $=003764756869440562565 \% 3$ Astm6e2kyn8o\&cof=FORID\%3A9 $\&$ ie $=$ UTF-8\&q $=$ picota\&sa $=$ Buscar

Jaramillo, M. L. (2005). Élite y naturaleza. ¿Naturaleza de elite? Nómadas (22), 86100.

Kant, I. (2007). ¿Qué es la ilustración? y otros escritos de ética, política y filosofía de la historia Immanuel Kant. (Trad. R. Rodríguez Aramayo). Madrid: Alianza.

Kirchheimer, O., y Rusche, G. (1984). Pena y estructura social. Bogotá, Colombia: Temis.

Lemert, E. M. (1964). Anomie and deviant behavior. Discussion and critique. London: Collier-Macmillan.

Melossi, D., y Pavarini, M. (1980). Cárcel y fábrica. Los orígenes del sistema penitenciario (siglos XVI-XIX). México: Siglo Veintiuno Editores.

Mouzo, K. (2012). Defensa social y resocialización: dos caras de una misma moneda. En M. H. Gutierréz (Ed.). Lápices o rejas. Pensar la actualidad del derecho a la educación en contextos de encierro (pp. 97-109). Buenos Aires: Editores del Puerto S.R.L.

Santoro, E. (2008). Cárcel y poder disciplinario: la reeducación mediante el trabajo. En E. Santoro (Ed.), Cárcel y sociedad liberal (pp. 12-24). Bogotá: Temis S.A. 